Abstract of a paper for presentation at the 9th AIAA Aviation Technology, Integration, and Operations Conference (ATIO) and Aircraft Noise and Emissions Reduction Symposium (ANERS), 21-24 September 2009, Hilton Head, South Carolina, USA

\title{
Climate impact evaluation as part of aircraft pre-design
}

\author{
Katrin Dahlmann ${ }^{1}$, Christine Fichter ${ }^{1}$, Volker Grewe ${ }^{1}$, Bernd Kärcher ${ }^{1}$, Robert Sausen ${ }^{1}$, \\ Ulrich Schumann ${ }^{1}$, Alexander Koch ${ }^{2}$, Volker Gollnick ${ }^{2}$ \\ ${ }^{1}$ Deutsches Zentrum für Luft- und Raumfahrt, Institut für Physik der Atmosphäre, \\ Oberpfaffenhofen, Germany \\ ${ }^{2}$ Deutsches Zentrum für Luft- und Raumfahrt, Institut für Lufttransportkonzepte und \\ Technologiebewertung, Hamburg, Germany
}

\section{Introduction}

Climate change is a challenge to society (IPCC, 2007). It is our responsibility to mitigate the climate impact. The climate impact of current air traffic is contributing in the range of 3 to $4 \%$ to global warming and is expected to grow further (e.g. Schumann, Grewe and Stenke, 2008). Air traffic is a part of human's mobility with an increasing rate in transport volume in the order of 5\% per year (Sausen et al., 2005). This implies the inclusion of climate metrics into the pre-design of new aircraft technologies (Egelhofer et al., 2008). Here we present a methodology, which allows for an optimisation of design aspect with regard to climate change. The approach includes aspects of aircraft pre-design, flight routings, costs and climate aspects, which are described in more detail in a companion paper by Koch et al. Here, we focus on the climate change aspect. We introduce the methodology and present the principle mechanism exemplarily with an application to aircraft emission inventories, which shows that although considerable uncertainties of the overall climate impact from air traffic exist, the difference between two emission sets can be determined with higher accuracy.

In the future, e.g. in the framework of projects like Clean Sky, etc. this approach can be applied to evaluate and possibly minimize the climate impact of new aircraft technology.

\section{Aircraft-induced perturbations and their uncertainties}

The climate impact of air traffic arises from a number of emission-related perturbations to the atmosphere. The perturbations and their estimated radiative forcing ( $\mathrm{RF})$, a measure of the climate change potential, are shown in Figure 1. Emissions of carbon dioxide $\left(\mathrm{CO}_{2}\right)$ and water vapor $\left(\mathrm{H}_{2} \mathrm{O}\right)$ lead to greenhouse warming. While $\mathrm{CO}_{2}$ accumulates in the global atmosphere due to its long life time and exerts a noticeable RF, the increase in atmospheric concentrations of $\mathrm{H}_{2} \mathrm{O}$, hence its climate effect, is small due to the short turnover times of a few weeks in the upper troposphere. Emissions of nitrogen oxides $\left(\mathrm{NO}_{\mathrm{x}}\right)$ give rise to chemical changes that manifest themselves in increases in ozone $\left(\mathrm{O}_{3}\right)$ concentrations (warming) on time scales of days to weeks and reductions in methane $\left(\mathrm{CH}_{4}\right)$ concentrations (cooling) on much longer time scales. Emitted soot particles produced during fuel combustion (mixed sulfate/organic particles forming in the exhaust plumes) lead to a slight warming (cooling) through absorption (scattering) of solar radiation, however the global climate effects are very small (Sausen, 2005). The generation of contrail cirrus leads to changes in cirrus cloud coverage and properties. Contrail cirrus develops from persistent line-shaped contrails that are accessible to measurements and leads to a positive RF through absorption of terrestrial radiation. Changes in cirrus microphysical properties can also be brought about by soot particle emissions acting as cloud-forming nuclei in the absence of contrails.

Little uncertainty exists in quantifying the RF from $\mathrm{CO}_{2}$ emissions, but the accuracy of climate change predictions will depend on the exact knowledge of total global fuel consumption by commercial and military aircraft. The perturbation by $\mathrm{H}_{2} \mathrm{O}$ emissions to the upper tropospheric moisture budget is difficult to be quantify exactly mainly due to the large 
variability of the latter, but perturbation is small. Current uncertainties in quantifying the exact amounts of the particulate emissions will not result in significant changes of the total aviation-induced RF because their contribution is small and partially cancel each other. The accurate quantification of the $\mathrm{NO}_{x}$-induced $\mathrm{O}_{3}$ changes is hampered by the incomplete understanding of the atmospheric distribution of reactive nitrogen and peroxy radicals that together determine the net photochemical production rate of $\mathrm{O}_{3}$. Uncertainties in $\mathrm{NO}_{\mathrm{x}}$ emission indices for the global fleet further contribute to the uncertainty of predicted $\mathrm{O}_{3}-$ induced RF changes. The estimate of $\mathrm{NO}_{\mathrm{x}}$-induced $\mathrm{CH}_{4}$ changes on $\mathrm{RF}$ is even more difficult to quantify because it involves chemical feedback mechanisms that develop over long time scales. Current estimates of line-shaped contrail RF are uncertain and probably represent lower limits. No reliable best estimates of the contribution of contrail cirrus and of soot effects on cirrus to climate change exist. Only recently a climate model representing contrail cirrus based on a physical treatment has become available. Parametric studies indicate a potential importance of the soot effect, but as long as the ice-forming properties of aircraft soot and other atmospheric particles are not well known, associated RF estimates remain speculative.

In sum, non- $\mathrm{CO}_{2}$ effects, in particular those arising from contrails and contrail cirrus, contribute largely to the overall aviation-induced climate change. Pending uncertainties currently preclude robust predictions, but recent developments in improving the representation of relative humidity, cirrus clouds, and chemistry in large-scale atmospheric models will yield more reliable estimates in the near future.

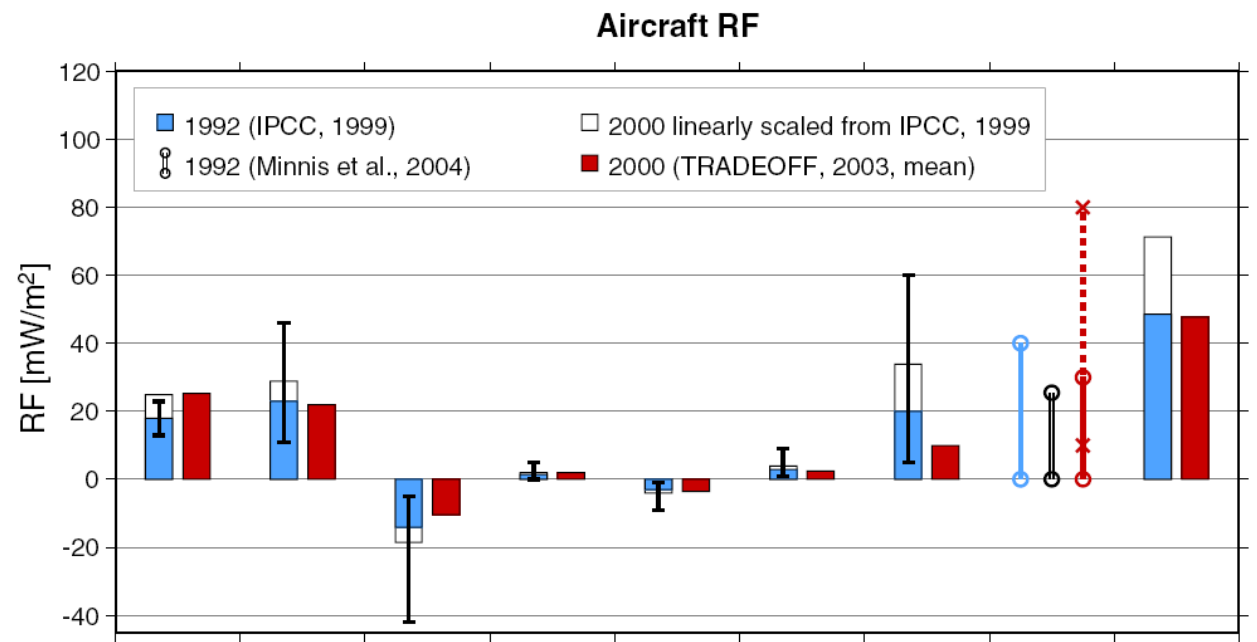

Fig. $1 \mathrm{RF}\left[\mathrm{mW} / \mathrm{m}^{2}\right]$ from aviation for 1992 (blue) and 2000 (white and red), based on IPCC, 1999) and TRADEOFF results (Sausen et al. 2005).

\section{AirClim - An efficient assessment tool}

AirClim is a model which comprises a linearization of atmospheric processes from the emission to radiative forcing, resulting in an estimate of near surface temperature change, which is presumed to be a reasonable indicator for climate change. The model is applicable to evaluate numerous air traffic scenarios, including different routings and technological options. For this the climate agents $\mathrm{CO}_{2}, \mathrm{H}_{2} \mathrm{O}, \mathrm{CH}_{4}$ and $\mathrm{O}_{3}$ (latter two resulting from $\mathrm{NO}_{\mathrm{x}}$-emissions) and contrails are taken into account. AirClim combines a number of precalculated atmospheric data with aircraft emission data to obtain the temporal evolution of atmospheric concentration changes, radiative forcing and temperature changes. An overview of the methodology is given in Fig. 2. The main part of the model AirClim is indicated in blue, 
showing the functional chain from emissions (yellow) and precalculated atmospheric input data (rose) to the resulting global mean near surface temperature change.

In the first step we define emission regions with a normalised (=equal for all regions) emission strength (in mass mixing ratios per time). For each of the idealised emission regions, a climate-chemistry simulation $(\mathrm{E} 39 / \mathrm{C})$ is performed employing normalised emissions of nitrogen oxides and water vapour to obtain its chemical response, i.e. the simultaneous effect of nitrogen oxides and water vapour. Then, in a second and third step chemical perturbations and radiative forcing of ozone, methane, water vapour, and contrails are calculated applying a state-of-the-art climate-chemistry model. These results are the precalculated atmospheric input data for AirClim. The benefit of this methodology is that the time expansive precalculations have only done once, and can than be used for any simulations.

The model AirClim combines the precalculated altitude and latitude dependent perturbations with emission data in order to calculate composition changes and near surface temperature changes caused by these emissions.

A detailed description and validation is given in Grewe and Stenke (2008). Here we apply an extended AirClim version, with a higher resolution, especially at cruise altitudes (Fichter,

2009).

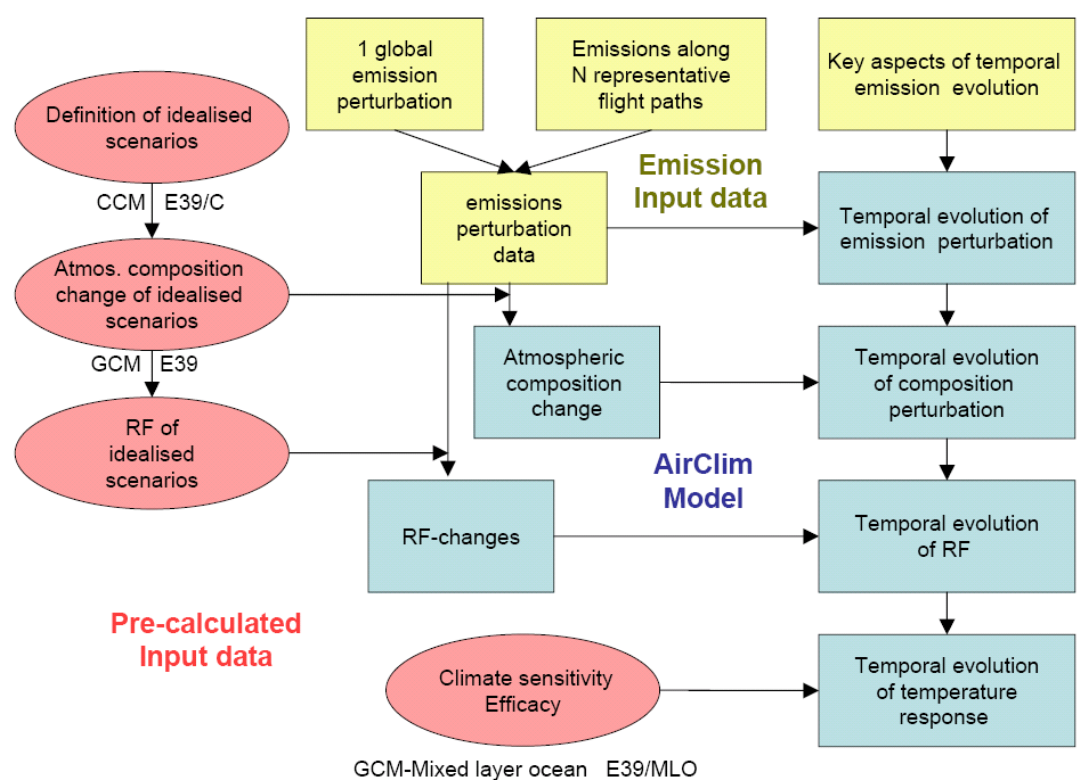

Fig. 2 Overview of the multi-step approach to derive near surface temperature changes and ozone depletion from emission scenarios (Grewe and Stenke, 2008).

\section{Climate impact evaluation as part of aircraft pre-design}

Exemplarily we analyze four different emission scenarios (TRADEOFF, NASA, Quantify and AERO2k) to show that small difference between two emission sets can be determined with higher accuracy, although considerable uncertainties of the overall climate impact exists. In order to analyze only the impact of differences in the vertical and horizontal distribution we scale the global fuel combustion and $\mathrm{NO}_{\mathrm{x}}$ emission of all emission scenarios to the same value. I.e. the only difference between the scenarios is the different geographical distribution. A temporal evolution according to the IPCC Fa1 scenario was assumed. The above mentioned uncertainties are taken into account in AirClim. For example, background concentrations of 
$\mathrm{CO}_{2}$ and $\mathrm{CH}_{4}$, stratospheric lifetime, Radiative forcing and climate sensitivities of each species are regarded uncertainties in the range of up to $50 \%$. The uncertainties are expressed as relative error and depend on scientific understanding of the according processes (e.g. error of $\mathrm{RF}(\mathrm{O} 3)=50 \%)$. The temperature change for two of the above mentioned emission scenarios caused by ozone with different RFs is presented in Figure 3. Due to the large uncertainties in RF, the difference in resulting temperature change is very large $(50-150 \mathrm{mK})$. Despite the large uncertainties the relative difference of both scenarios $(7 \%)$ is quit unaffected of the used RF. For better quantifying the uncertainty of the absolute temperature change a Monte-Carlo-Simulation was carried out. For every uncertainty parameter a gauss distributed random number inside the error bars is used. By this a broad range of possible combinations of the uncertainty parameters is calculated. The resulting temperature changes of the four emission scenarios are presented in Figure 4 as frequency distributions. Due to the large uncertainties in resulting temperature changes at least TRADEOFF and Quantify scenarios do not differ significantly. However, the distributions are correlated as already suggested in Figure 3. For better discrimination of the temperature changes of different emission scenarios we calculate the percentage difference of the scenario in comparison to the mean of all scenarios for every step of the Monte-Carlo-Simulation. The higher this factor, the larger the climate impact of the scenario. This factor is presented in Figure 5. Despite the large uncertainty in temperature change, all scenarios can significantly be differentiated through this kind of presentation. Although the global emission of $\mathrm{CO}_{2}$ and $\mathrm{NO}_{\mathrm{x}}$ is the same in all four scenarios, the climate impact differs clearly. This shows that the knowledge of the exact emission region is important to determine the climate impact of an aircraft flight.

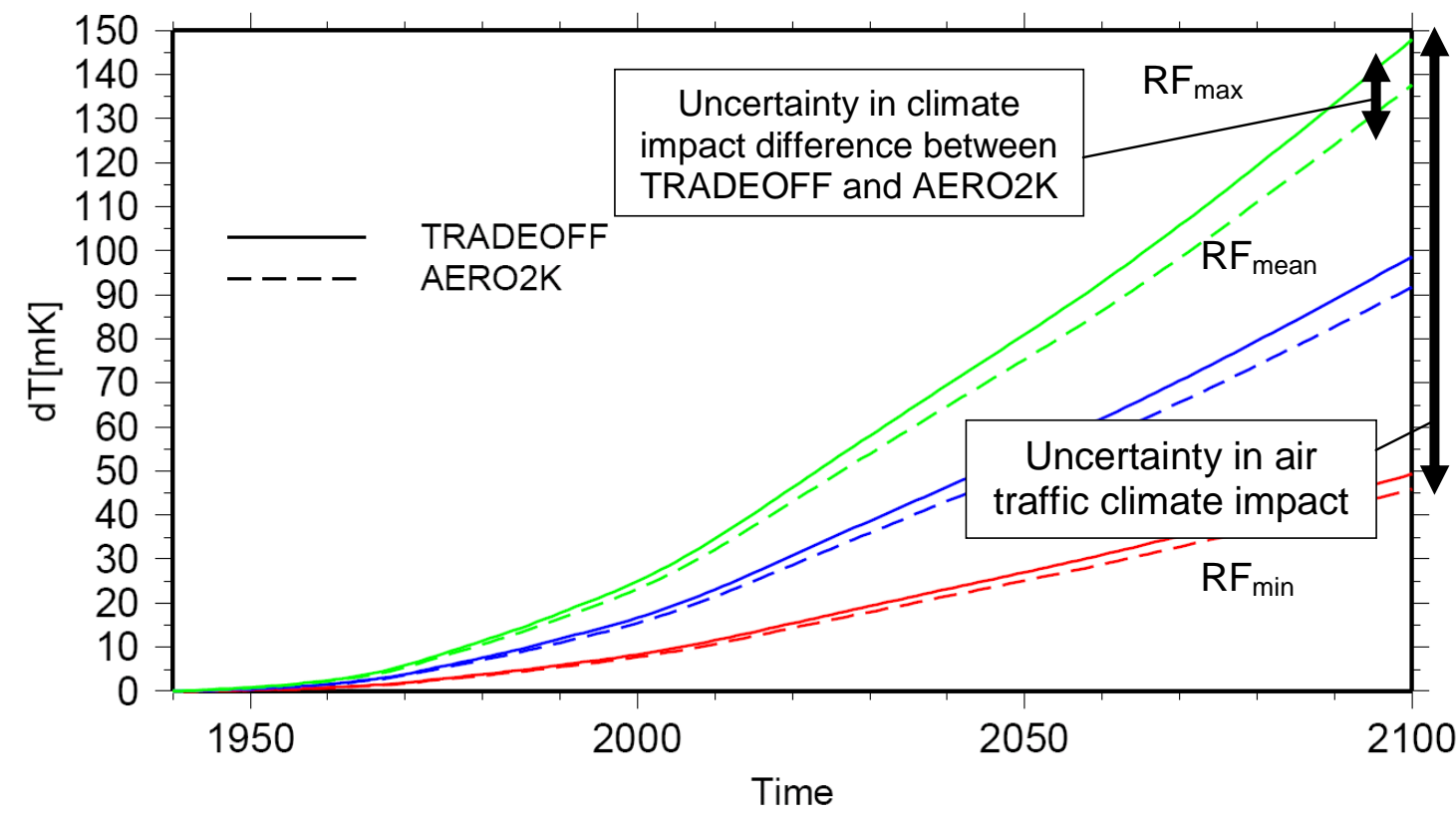

Fig. 3 Temperature change [mK] due to ozone of TRADEOFF and AERO2k database with different RF values $\left(R F_{\text {max }}\right.$ green, $R F_{\text {mean }}$ blue and $R F_{\text {min }}$ red). The arrows indicate uncertainty ranges for the uncertainty in the air traffic climate impact (large arrow) and the uncertainty in the difference in the climate impact from 2 emission distributions (small arrow). 


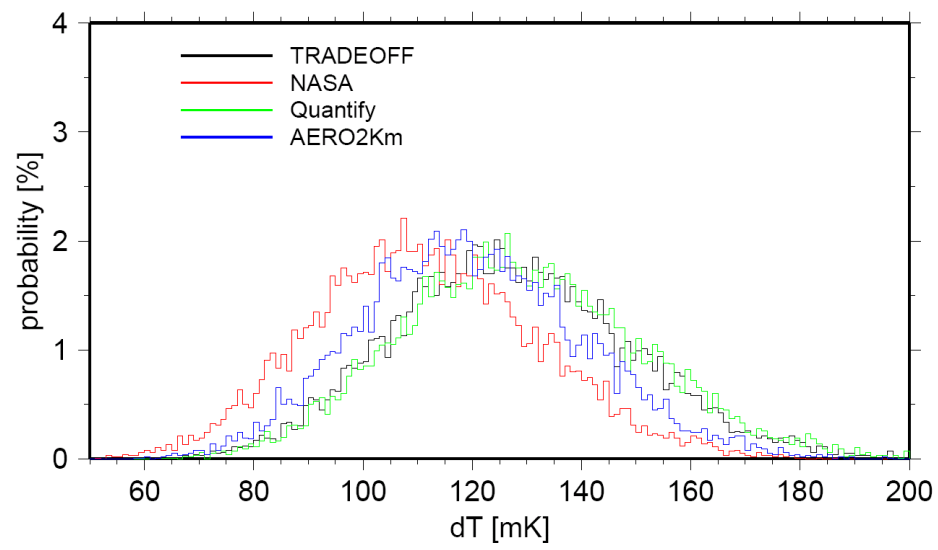

Fig. 4 Probability density function of temperature change [mK] of TRADEOFF (black), NASA (red), Quantify (green) and AERO2k (blue)

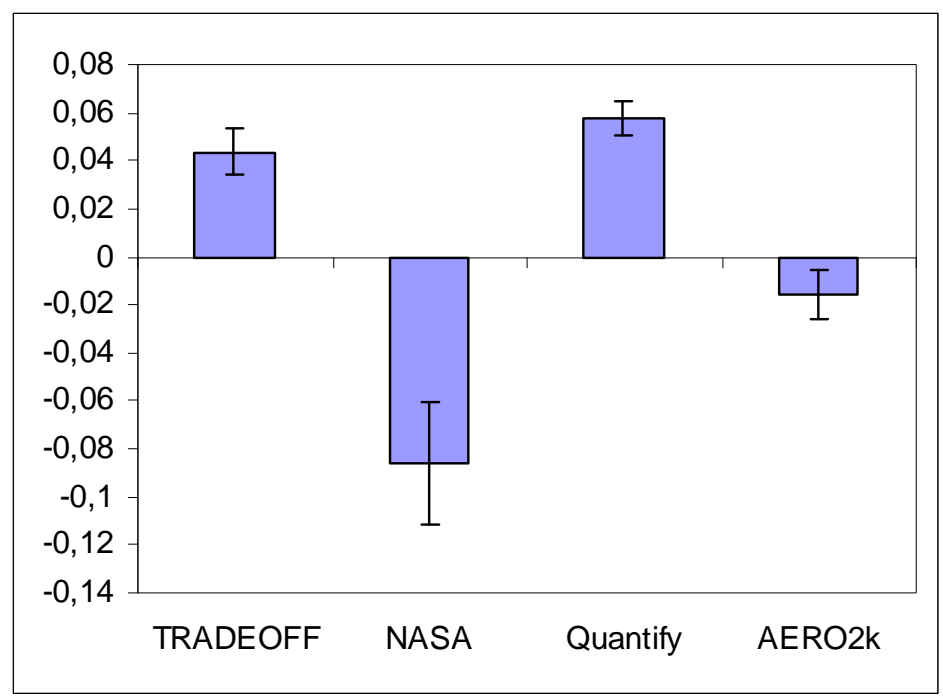

Fig. 5 Percentage difference of TRADEOFF, NASA, Quantify and AERO2k scenario in comparison to the mean of all scenarios. Presented error bars according to the standard deviation.

\section{Conclusions and Outlook: Future Applications}

The AirClim model is an efficient tool to study the climate impact of different technology options and routings and can be included in the pre-design of aircraft. The whole process, as e.g. described in a companion paper by Koch et al., comprises a detailed multi-disciplinary aircraft design tool, a mission and 3D flight routing calculation, an engine performance emission tool, and a 3D calculation of aircraft emissions of $\mathrm{CO}_{2}, \mathrm{H}_{2} \mathrm{O}, \mathrm{NO}_{\mathrm{x}}$, and particles. Metrics used to evaluate the design are life cycle costs, cosmic radiation exposure, and climate change estimates. Here we focused on the climate change estimates. Uncertainties in the estimate of climate change caused by air traffic are generally large, which, however, does not impede the inclusion of a climate change metric in to the pre-design. As a test case, we selected four estimates of current air traffic emissions and scaled the absolute amount of the global annual mean emissions to the same value. Hence the only difference occurs in the regional distribution. Even with these emission data, significantly different climate impacts can be detected employing a wide range of uncertainties in atmospheric processes (see Figure 5). Hence, the methodology is applicable within aircraft pre-design. 
Abstract of a paper for presentation at the 9th AIAA Aviation Technology, Integration, and Operations Conference (ATIO) and Aircraft Noise and Emissions Reduction Symposium (ANERS), 21-24 September 2009, Hilton Head, South Carolina, USA

Future applications will include an analysis of the air traffic system with respect to climate change and future mitigation options with respect to flight levels and routing. A first application was performed within the EU project HISAC for supersonic business jet configurations. In the future we plan to apply these tools in close cooperation with industry, e.g. in the framework of CLEAN SKY and other projects.

\section{References}

1 Egelhofer, R., Marizy, C. and Bickerstaff, C.: On how to consider climate change in aircraft design, Meteorol. Z. 17, 173-179, 2008.

2 Fichter, C. (2009): Climate Impact of Air Traffic Emissions in Dependency of the Emission Location. PhD thesis, Manchester Metropolitan University

3 Grewe, V. and A. Stenke, AirClim: an efficient climate impact assessment tool, Atmospheric Chemistry and Physics, 8, 4621 - 4639, 2008.

4 IPCC: Aviation and the global atmosphere, Intergovernmental Panel on Climate Change, Cambridge University Press, New York, USA, 1999.

5 IPCC: Climate Change 2007 - The physical science basis, Intergovernmental Panel on Climate Change, Cambridge University Press, New York, USA, 2007.

6 Sausen, R., Isaksen, I., Grewe, V., Hauglustaine, D., Lee, D.s., Myhre, G., Köhler, M.O., Pitari, G., Schumann, U., Stordal, F., and Zerefos, C., Aviation Radiative forcing in 2000: An Update on IPCC (1999), Meteorol. Z. 14, 555-561, DOI: 10.1127/0941-2948/2005/0049, 2005.

7 Schumann, Ulrich (2008): Luftverkehr und Klima. Physik in unserer Zeit, 39 (3), Wiley-VCH Verlag, Weinheim, p. 143 - 149, DOI 10.1002/piuz.200801168

\section{Acknowledgments}

This work was performed within the DLR-project "Climate-compatible air transport system (CATS)". 